\title{
A comparative study of food intake patterns and health indicators between Japanese Americans and Native Japanese \\ - A comparison of incidence of atherosclerosis related indicators between two population Groups-
}

\author{
Kazuko MAEDA ${ }^{1}$, Migiko TAKANOHASHI ${ }^{2}$, Suniko KURATA ${ }^{3}$, \\ Kenji SUZUKI ${ }^{4}$ and Tsukasa NAMEKATA ${ }^{5}$
}

Changes of diet and life style can provide substantial effects on health status. The objective of this study was to investigate this kind of effect, and to obtain some suggestions for constructing healthy life style.

We compared the results of detailed questionnaire which was designed to clarify the characteristics of daily life and diet pattern, and measurement of aortic pulse wave velocity between the native Japanese residents continuously living in Japan and Japanese Americans living in Seattle, USA. The former was a population group who had sustained their traditional life style and the latter was a group who had mostly changed their life-styles.

There were many differences between two population groups in their dietary habits. Japanese Americans were fond of foodstuffs rich in fat much more than native Japanese. And this characteristcs of Japanese American's dietary habit seemingly increase the prevalence of arteriosclerosis among them. It may suggest that Japanese Americans in Seattle have problems in their daily food intake.

Key words : pulse wave velocity, nutrition, life style, athroscrelosis, Native Japanese, Japanese American

\section{Introduction}

For the past several decades diet patterns and life style of the Japanese people have been gradually changed towards western patterns particularly among the youth. Due to such changes, the average serum total cholesterol level in the Japanese population has increased $12.2 \mathrm{mg} / \mathrm{dl}$ for men and $16.0 \mathrm{mg} / \mathrm{dl}$ for 30 years old and over from 1980 to 1990 according to the national surveys (Kosei no shihyou, 1993). It may be predictable that an increase in prevalence of some

\footnotetext{
${ }^{1}$ Private Research Institute of Epidemiology

${ }^{2}$ Minato Public Health Center

${ }^{s}$ Musashigaoka College

${ }^{4}$ Epidemiological Arteriosclerosis Reseach Institute in Japan, Labor-Cultural Association

${ }^{5}$ Pacific Rim Disease Prevention Center
} 


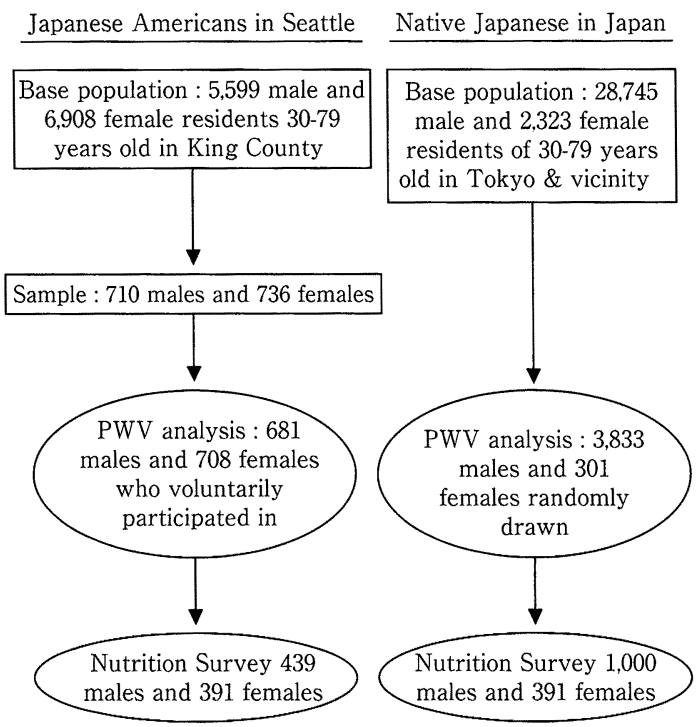

Figure 1 Study Sample

chronic disease occurs in Japan in the future. One way to measure the effects of environmental changes including diet and lifestyle (smoking, drinking, physical activities and others) on disease indicators or disease itself is to compare native Japanese and Japanese Americans who have the same generic background as but different lifestyle from native Japanese in Japan.

In this study, we compared the results of the surveys on eating habit (diet and eating behavior) and lifestyle (smoking, drinking) and the screening results of serum lipid levels and the aortic pulse wave velocity (PWV) between Japanese Americans in Seattle, U.S.A. and native Japanese in Japan.

\section{Subjects and Methods}

The study subjects in Seattle were comprised of 710 male and 736 female Japanese-American residents who participated in cardiovascular disease prevention screening at the Pacific Rim Disease Preventive Center (PDPC) (Figure 1).
Among 1446 participants, 439 males and $391 \mathrm{fe}$ males participated in the survey on eating habits. The study subjects in Japan consisted of 4,134 native Japanese males and females randomly selected from 31,068 people who underwent the disease prevention screening at the Epidemiological Arteriosclerosis Research Institute (EARI), Japan Labor-Cultural Association. More male-workers underwent the check up than female-workers, reflecting current labor situations in which male workers greatly outnumber female workers in Japan. Among 31,068 native Japanese who were randomly selected, 1,000 males and 841 females participated in the survey on eating habits.

Based on the screening results in both Seattle and Japan, we included examinations of the PWV, serum lipids and lipoproteins, total cholesterol [TC], high density lipoprotein cholesterol [HDL-C], low density lipoprotein cholesterol [LDL-C], triglycerides [TG] and blood pressure in the analysis. To minimize the possible measure- 

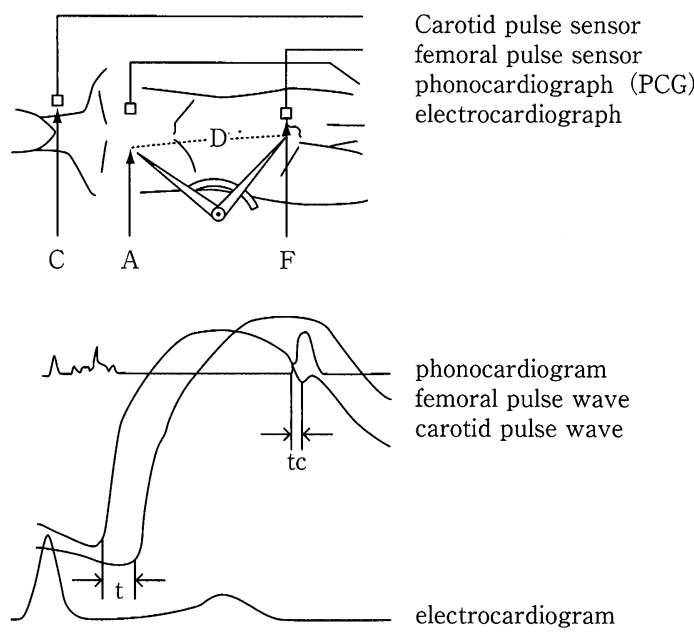

$$
\mathrm{PWV}=\left[\frac{\mathrm{D} \times 1.3}{\mathrm{t}+\mathrm{tc}}\right]_{\mathrm{p}} \mathrm{m} / \mathrm{sec}
$$

Figure 2 Method for measuring the aortic pulse wave velocity (PWV)

ment bias, measuring PWV in Seattle was conducted by the medical technicians who were trained at the EARI. All PWV records were sent to the EARI and validated by the same criteria used for native Japanese subjects.

Regarding measurement of serum lipid concentrations, we followed the quality control guideline set by the U.S. Centers for Disease Control and Prevention (CDC): frozen testing serum samples were sent from Seattle to the EARI for quality control testing to confirm that values measured at the EARI were acceptable. Serum lipid samples collected at the PDPC in Seattle were analyzed at the University of Washington Northwest Lipid Research Laboratory, which is the CDC's designated core laboratory.

With regard to PWV, it has long been pointed out that PWV is closely related to modulus of elasticity of the arterial wall (Hallcock, 1934). Ex- perimental and theoretical grounds for PWV as a noninvasive and quantitative indicator for atherosclerosis were established by Hasegawa (Hasegawa et al., 1970). Furthermore, Otsuka (1973) observed that atherosclerosis is absent for PWV values of less than $8 \mathrm{~m} / \mathrm{sec}$ d and present for greater than $9 \mathrm{~m} / \mathrm{second}$ on the basis of the association between ante mortem PWV values and postmortem pathological observations in aortic arteries among 169 cases. Morishita et al. (1985) followed up patients having onset of cerebrovascular and cardiovascular diseases for one year, and reported significantly high PWV values in those with such diseases than in those without. The PWV measuring method is illustrated in Figure 2. The present study used PWV-200 manufactured by Fukuda Denshi Co., Ltd. Abnormal PWV value was defined as not less than $8.0 \mathrm{~m} /$ second for those aged under 60 
Table 1 Characteristics of Japanese Americans in Seattle, Washington U.S.A. and native urban Japanese in Japan who participated in screening

\begin{tabular}{|c|c|c|c|c|c|c|}
\hline & \multicolumn{4}{|c|}{ Japanese American } & \multicolumn{2}{|c|}{ Native Japanese } \\
\hline & males & $\mathrm{N}=710$ & females & $\mathrm{N}=728$ & males & $\mathrm{N}=3,833$ \\
\hline & Mean & $\mathrm{SD}$ & Mean & $\mathrm{SD}$ & Mean & $\mathrm{SD}$ \\
\hline Age & 56.4 & 13.7 & 55.9 & 13.6 & $55.6 *$ & 7.7 \\
\hline BMI $(\mathrm{kg} / \mathrm{m} 2)$ & 25.7 & 3.2 & 24.0 & 3.8 & $23.8 * *$ & 2.7 \\
\hline $\mathrm{TC}(\mathrm{mg} / \mathrm{dl})$ & 224.1 & 37.8 & 227.3 & 41.6 & $191.1 * *$ & 32.4 \\
\hline LDL-C (mg/dl) & 139.1 & 35.3 & 135.0 & 38.0 & $108.6 * *$ & 31.1 \\
\hline HDL-C $(\mathrm{mg} / \mathrm{dl})$ & 51.0 & 14.0 & 63.2 & 16.7 & $55.4 * *$ & 14.3 \\
\hline Triglycerides $(\mathrm{mg} / \mathrm{dl})$ & 169.8 & 158.6 & 143.9 & 120.5 & $135.6 *$ & 101.3 \\
\hline TC/HDL ratio & 4.7 & 1.4 & 3.9 & 1.3 & $3.7 * *$ & 1.1 \\
\hline \multirow[t]{2}{*}{ Alcohol (g/day) } & 5.8 & 11.9 & 1.3 & 4.6 & $27.3 * *$ & 22.2 \\
\hline & Number & $(\%)$ & Number & $(\%)$ & Number & $(\%)$ \\
\hline Drinking Habit & & & & & & $(* *)$ \\
\hline Non-drinkers & 257 & 36.2 & 389 & 53.4 & 686 & 17.9 \\
\hline$<1 \mathrm{drink} /$ week & 157 & 22.1 & 212 & 29.1 & 378 & 9.9 \\
\hline 1-6 drink/week & 157 & 22.1 & 98 & 13.5 & 621 & 16.2 \\
\hline 1-2 drink/week & 89 & 12.5 & 24 & 3.3 & 516 & 13.5 \\
\hline 3-5 drink/week & 44 & 6.2 & 4 & 0.5 & 1015 & 26.5 \\
\hline$>5$ drink/week & 6 & 0.8 & 1 & 0.1 & 617 & 16.1 \\
\hline Smoking & & & & & & $(* *)$ \\
\hline Non-smokers & 265 & 37.3 & 512 & 70.3 & 1355 & 35.4 \\
\hline Current Smokers & 109 & 15.4 & 66 & 9.1 & 1762 & 46.0 \\
\hline Ex-smokers & 336 & 47.3 & 150 & 20.6 & 716 & 18.7 \\
\hline Hypertensive Medication & 102 & 14.4 & 112 & 15.4 & 413 & $10.3(* *)$ \\
\hline
\end{tabular}

$* \mathrm{p}<0.05, * * \mathrm{p}<0.01$ by t-test, $(* *) \mathrm{p}<0.01$ by $\chi^{2}$ test

$P$ show the statistical differences between Japanese American men \& Native Japanese men

years and greater than $9.0 \mathrm{~m} / \mathrm{second}$ for those aged 60 years and over (coded " 1 " for abnormality and " 0 " for no abnormality), based on the study findings from showing the association between PWV and other atherosclerotic indicators such as hypertension, abnormal arteriolar changes in the retina and ischemic changes in ECG (Suzuki et al., 1996; Namekata et al., 1995; Namekata et al., 1997).

Japanese American were instructed to fill out, before or after screening, a questionnaire asking age, generation, occupation, past history and risk factors, while native Japanese answered a simple self-recording questionnaires developed by the
EARI. Data were analyzed only for the questions contained in both questionnaires. The instruments for the survey on eating habits were the Japanese questionnaire developed by the EARI for native Japanese and the English one developed jointly by the PDPC and the EARI for Japanese Americans.

Since the questionnaire on nutrition intake for Japanese Americans was newly developed for the present study, its effectiveness had to be confirmed. For that purpose, 75 Japanese Americans were asked to keep records of food items they consumed, the amount and the frequency of consuming each item for four days, including a 


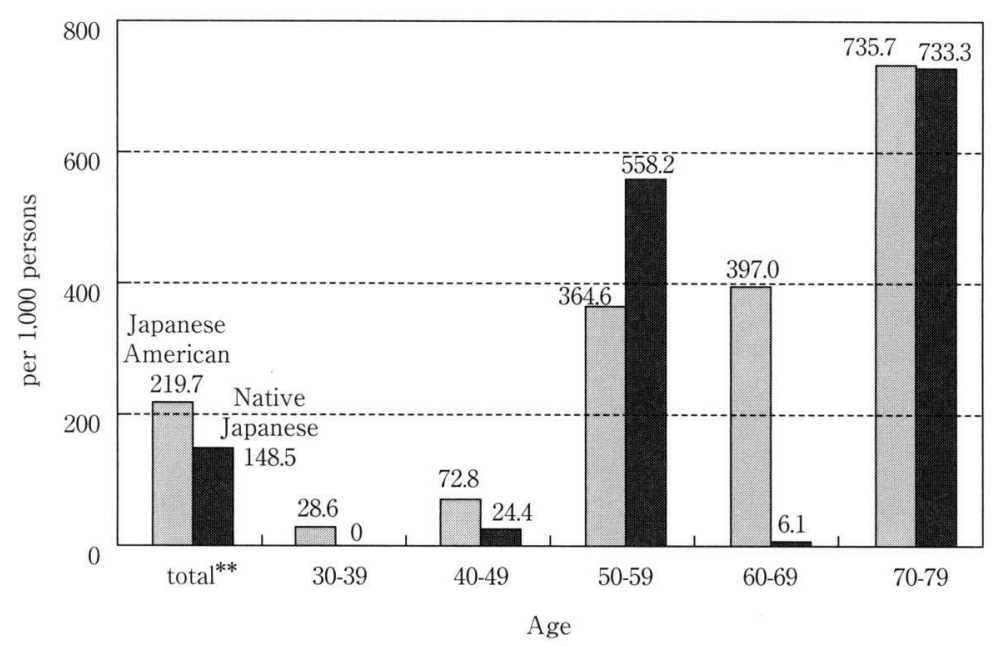

Figure 3 Prevalence of Abnormally High* PWV among Japanese Americans and Native Japanese (males and females combined)

*Abnormally high PWV was defined as $>8.0 \mathrm{~mm} / \mathrm{sec}$ for $<60$ years of age and $>9.0 \mathrm{~m} / \mathrm{sec}$ for $\geq 60$ years of age.

**Age-adjusted

Table 2 Odds ratio for presence of abnormally high PWV among Japanese Americans in Seattle, U.S.A. and native urban Japanese

\begin{tabular}{lrll}
\hline \multicolumn{1}{c}{ Variable } & Reference & $\begin{array}{c}\text { Japanese } \\
\text { Americans }\end{array}$ & $\begin{array}{c}\text { Native } \\
\text { Urban Japanese }\end{array}$ \\
\hline Sex & Female-1.0 & $0.65^{* *}$ & 0.98 \\
Age & $<60-1.0$ & $3.60^{* * *}$ & $0.07^{* * *}$ \\
BMI & $<27-1.0$ & 1.08 & $1.34^{* *}$ \\
Hypertension & no-1.0 & $2.01^{* * *}$ & $2.76^{* * *}$ \\
TC/HDL-C ratio & $<4.5-1.0$ & $1.61^{* * *}$ & $1.28^{* *}$ \\
Diabetes & no-1.0 & $3.66^{* * *}$ & $2.43^{* * *}$ \\
Current drinkers & no-1.0 & $0.45^{* * *}$ & 0.85 \\
Ex-drinkers & no-1.0 & $0.47^{* * *}$ & 1.07 \\
Current smokers & no-1.0 & 1.47 & 1.05 \\
Ex-smokers & no-1.0 & $1.65^{* *}$ & 1.05 \\
\hline
\end{tabular}

${ }^{*} \mathrm{p}<0.05, * * \mathrm{p}<0.01,{ }^{* * *} \mathrm{p}<0.001$

weekend

The statistical methods used were t-tests for average comparisons and $\chi 2$ tests for frequency comparisons. Multiple logistic regression analysis was used to examine the association between PWV and its risk factors, reference levels as the standard were fpllowed with the most popular numerical values used in the U.S. (Ulene, 1989).

\section{Results}

Table 1 compares variables between Japanese American men and native Japanese men. Most 
Table 3 Average nutrition intake of the 4-day food diary among 75 Japanese Americans in Seattle

\begin{tabular}{|c|c|c|c|c|c|c|c|c|c|c|c|c|c|}
\hline \multirow{3}{*}{\multicolumn{2}{|c|}{$\frac{\text { Sex }}{\text { Age }}$}} & \multicolumn{6}{|c|}{ Male } & \multicolumn{6}{|c|}{ Female } \\
\hline & & \multicolumn{2}{|c|}{$\sim 39$} & \multicolumn{2}{|c|}{$40 \sim 59$} & \multicolumn{2}{|c|}{$60 \sim$} & \multicolumn{2}{|c|}{$\sim 39$} & \multicolumn{2}{|c|}{$40 \sim 59$} & \multicolumn{2}{|c|}{$60 \sim$} \\
\hline & & Mean & $\mathrm{SD}$ & Mean & $\mathrm{SD}$ & Mean & $\mathrm{SD}$ & Mean & $\mathrm{SD}$ & Mean & $\mathrm{SD}$ & Mean & $\mathrm{SD}$ \\
\hline Height & $\mathrm{cm}$ & 172.8 & 3.6 & 169.9 & 4.7 & 168.8 & 7.4 & 156.6 & 8.1 & 156.5 & 4.9 & 155.9 & 5.3 \\
\hline Weight & $\mathrm{kg}$ & 67.5 & 7.8 & 73.5 & 11.1 & 71.7 & 8.9 & 51.2 & 5.1 & 54.7 & 7.8 & 54.9 & 4.2 \\
\hline Caloric Consumption & Kcal & 2419 & 286 & 264.3 & 436 & 2744 & 530 & 1964 & 349 & 2008 & 378 & 2186 & 532 \\
\hline Energy & Kcal & 1911 & 336 & 215.1 & 513 & 2184 & 371 & 1858 & 292 & 1692 & 431 & 1778 & 416 \\
\hline Carbohydrate & $\mathrm{g}$ & 233.6 & 65.9 & 271.3 & 67.4 & 288.4 & 32.9 & 267.2 & 66.6 & 227.8 & 64.1 & 265.6 & 98.8 \\
\hline Carbohydrate/Energy & $\%$ & 48.4 & 7.3 & 51.0 & 7.4 & 53.9 & 8.7 & 57.0 & 7.6 & 53.8 & 5.3 & 58.0 & 7.6 \\
\hline Total-Fat & $\mathrm{g}$ & 64.9 & 15.3 & 75.2 & 25.4 & 68.4 & 26.4 & 57.9 & 13.7 & 54.5 & 17.2 & 48.6 & 7.0 \\
\hline Total-Fat/Energy & $\%$ & 30.5 & 5.3 & 31.0 & 4.3 & 27.3 & 5.7 & 28.3 & 6.3 & 28.9 & 4.7 & 25.9 & 6.4 \\
\hline Mono & $\mathrm{g}$ & 18.4 & 6.1 & 19.2 & 9.4 & 16.0 & 8.7 & 13.5 & 5.9 & 12.7 & 4.6 & 11.9 & 3.1 \\
\hline Poly & $\mathrm{g}$ & 9.8 & 3 & 9.2 & 3.9 & 12.0 & 4.9 & 8.1 & 4.8 & 7.1 & 3.0 & 7.7 & 2.4 \\
\hline Saturated Fat & $\mathrm{g}$ & 18.9 & 4.9 & 22.8 & 9.5 & 17.8 & 11.0 & 16.1 & 4.4 & 16.4 & 6.5 & 13.9 & 2.6 \\
\hline Protein & $\mathrm{g}$ & 89.2 & 18.5 & 93.3 & 32.5 & 101.3 & 21.5 & 74.3 & 12.1 & 76.6 & 20.1 & 72.1 & 21.1 \\
\hline Protein/Energy & $\mathrm{g}$ & 18.9 & 3.3 & 17.2 & 2.9 & 18.5 & 1.4 & 16.2 & 2.7 & 18.2 & 2.6 & 16.3 & 3.2 \\
\hline Vitamin-A & $\mathrm{IU}$ & 9317 & 4257 & 10068 & 6483 & 14351 & 6609 & 15179 & 12003 & 13353 & 8018 & 23208 & 13813 \\
\hline Vitamin-B1 & $\mathrm{mg}$ & 1.9 & 0.8 & 1.5 & 0.4 & 2.3 & 0.8 & 1.7 & 0.7 & 1.6 & 0.6 & 2.1 & 1.1 \\
\hline Vitamin-B2 & $\mathrm{mg}$ & 2 & 1.1 & 1.8 & 0.7 & 2.6 & 1.0 & 1.8 & 0.8 & 1.7 & 0.8 & 2.2 & 1.3 \\
\hline Vitamin-C & $\mathrm{mg}$ & 251.5 & 378.5 & 163.6 & 124.0 & 299.5 & 215.2 & 196.4 & 160.4 & 210.2 & 137.0 & 287.9 & 191.4 \\
\hline $\mathrm{NaCl}$ & $\mathrm{g}$ & 10.6 & 5.4 & 10.9 & 3.3 & 10.4 & 4.0 & 10.0 & 2.6 & 9.2 & 2.1 & 8.5 & 2.3 \\
\hline Calcium & $\mathrm{mg}$ & 564.7 & 174.9 & 952.1 & 670.7 & 1020 & 475.4 & 755.3 & 258.8 & 727.7 & 276.0 & 804.7 & 419.7 \\
\hline Potassium & $\mathrm{mg}$ & 2588 & 741 & 3137 & 782 & 4234 & 649 & 3025 & 1124 & 2961 & 875 & 3023 & 1232 \\
\hline Magnesium & $\mathrm{mg}$ & 264.9 & 107.1 & 251.4 & 76.3 & 343.6 & 67.1 & 243.0 & 100.8 & 245.5 & 62.5 & 267.3 & 128.5 \\
\hline Iron & $\mathrm{mg}$ & 20.9 & 10.4 & 18.9 & 5.8 & 24.0 & 9.0 & 19.5 & 10.7 & 17.7 & 7.8 & 22.4 & 12.5 \\
\hline Cholesterol & $\mathrm{mg}$ & 337.2 & 77.2 & 317.0 & 109.2 & 283.2 & 125.1 & 253.1 & 92.2 & 245.3 & 86.2 & 197.1 & 85.7 \\
\hline Alcohol & $\mathrm{g}$ & 6.6 & 4.5 & 5.9 & 11.8 & 7.9 & 12.2 & 1.2 & 3.6 & 2.5 & 4.3 & 4.6 & 6.5 \\
\hline Alcohol/Energy & $\%$ & 2.6 & 1.9 & 2.0 & 3.8 & 2.5 & 3.9 & 0.5 & 1.5 & 1.2 & 2.1 & 2.2 & 3.1 \\
\hline Diet-Fiber & $\mathrm{g}$ & 2.1 & 1.3 & 3.7 & 1.6 & 5.5 & 2.1 & 3.5 & 2.4 & 4.0 & 2.5 & 5.2 & 1.9 \\
\hline
\end{tabular}

variables showed significant difference in their means between the two population groups implying higher risk for accelerating atherosclerosis among Japanese American men than among native Japanese men. Figure 3 compares prevalence of PWV abnormality between the two population groups by age. Prevalence of abnormally high PWV was high among Japanese American for all age-groups except for 50-59 years of age. Age-adjusted prevalence of abnormally high PWV was 219.7 per 1,000 persons in Japanese Americans, as compared with 148.5 per 1,000 persons in native Japanese. Consequently, the degree of atherosclerosis seems to be more accelerated for their age in Japanese Americans than in native Japanese (Table 1, Figure 3).

Table 2 shows the relationship of abnormally high PWV with possible risk factors, as expressed in odds ratio. In Japanese Americans, all variables except body mass index (BMI) and current smoking were significantly related to abnormally high PWV. The possible reason for lower risk of abnormally high PWV in males is longevity of females or higher survival rate of stronger males. In contrast, variables that were significantly related to abnormally high PWV in native 
Table 4 Frequency of person in categories of shortage, adequate, or excessive nutrition intake based on the 4-day food diary survey among 75 Japanese Americans in Seattle

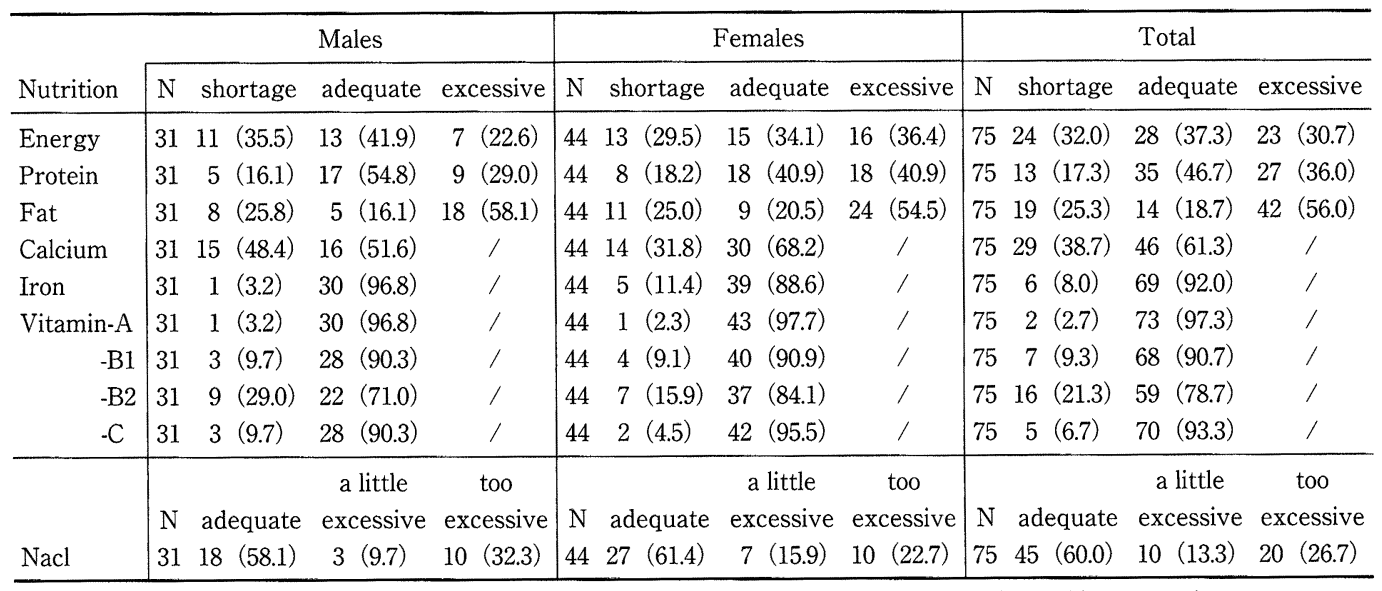

The range of adequate intake $=($ daily intake/daily recommended dietary allowance $($ RDAs $)) \times 100: 1)$ Energy and Fat : 80-100\%, 2) Protein : 80-120\%, 3) Calcium, Iron, Vitamin-A, Vitamin-B1, Vitamin-B2, Vitamin-C : 100\% $(10 \mathrm{~g}) \geqq$

Japanese included age, BMI, hypertension, $\mathrm{TC} / \mathrm{HDL}$ ratio and diabetes; current drinking was close to significance level.

However, the logistic model did not reveal the involvement of smoking as higher risk of abnormally high PWV. In contrast, previous smoking was significantly related to abnormally high PWV in Japanese Americans. This can be explained by the fact that in a population with high total cholesterol, the effect of smoking on atherosclerosis is likely to be magnified (Ball and Mann, 1988) and that mean total cholesterol of Japanese American is considerably higher than that of native Japanese. In the logistic model, PWV was significantly related to most of the known atherosclerotic risk factors, showing its appropriateness as the indicator of aortic atherosclerosis.

Table 3 presents the mean nutritional intake, as determined on the basis of the four-day food diary. Table 4 shows distribution of participants into three levels of nutrition intake; "deficient," "adequate" or "excessive". Table 5 shows corre- lation coefficients (Pearson's product moment correlation coeffecient) between daily mean intake of specific nutrients, as determined on the basis of the four-day food diary, and responses to the corresponding questions in the questionnaire on eating habits, developed for Japanese Americans. Since correlation coefficients were within 0.2 to 0.5 and were significant or close to significance for all nutrients, the eating-habits questionnaire developed for Japanese Americans is considered to moderately reflect actual nutritional intake. One unique feature of this questionnaire is that it is designed to assess nutritional intake conditions not only from foods consumed. but also from eating habits. For example, the habit of skipping breakfast or lunch leads to a decrease in the amount of energy and vitamin B1, B2 and C intake. "Eating out frequently" indicates a tendency toward deficiencies in vitamin $\mathrm{A}$ and calcium.

To compare nutritional intake conditions of Japanese Americans with those of native Japan- 
Table 5 Correlation coefficients between specific nutrient intake of 4-day diary results and responses from its related question of the questionnaire developed among 75 subjects

\begin{tabular}{|c|c|c|c|c|c|}
\hline $\begin{array}{l}\text { Between daily average intake of } 4 \text {-day } \\
\text { food diary and response to a specific } \\
\text { question in questionnaire }\end{array}$ & $\begin{array}{l}\text { correlati- } \\
\text { on coef- } \\
\text { ficient }\end{array}$ & p-value & $\begin{array}{l}\text { Between daily average intake of } 4 \text {-day } \\
\text { food diary and response to a specific } \\
\text { question in questionnaire }\end{array}$ & $\begin{array}{l}\text { correlati- } \\
\text { on coef- } \\
\text { ficient }\end{array}$ & p-value \\
\hline Between total energy intake and: & & & Between total intake of vitamin $\mathrm{B} 1$ and: & & \\
\hline 1. Frequency of seafood consumption & -0.352 & 0.008 & 1. Freq. of eating canned fish products & 0.280 & 0.038 \\
\hline 2. Freq. of shellfish consumption & -0.333 & 0.013 & 2. Freq. of eating potatoes & -0.288 & 0.003 \\
\hline \multirow{2}{*}{$\begin{array}{l}\text { 3. Freq. of canned fish product con- } \\
\text { sumption }\end{array}$} & 0.341 & 0.011 & 3. Amount of fruits consumption & 0.272 & 0.045 \\
\hline & 0.323 & 0.016 & $\begin{array}{l}\text { 4. Freq. of skipping meals (less skip- } \\
\text { ping }+ \text { ) }\end{array}$ & 0.260 & 0.056 \\
\hline $\begin{array}{l}\text { 4. Freq. of eating deep fried, broiled or } \\
\text { smoked seafood }\end{array}$ & 0.020 & 0.0 .10 & 5. Amount of eating vitamin $C$ rich fruits & 0.264 & 0.051 \\
\hline 5. Freq. of skipping meals (less skipping) & 0.266 & 0.049 & 6. BMI & 0.219 & 0.108 \\
\hline 6. BMI & 0.440 & 0.001 & & & \\
\hline \multirow[t]{2}{*}{ 7. Energy consumption } & 0.477 & 0.000 & Between total vitamin $\mathrm{B} 2$ intake and: & & \\
\hline & & & 1. Freq. of eating seafood & 0.226 & 0.097 \\
\hline $\begin{array}{l}\text { Between total protein intake and: } \\
\text { 1. Frequency of seafood consumption }\end{array}$ & -0.334 & 0.013 & $\begin{array}{l}\text { 2. Freq. of eating tofu, abura-age and } \\
\text { soy milk }\end{array}$ & -0.221 & 0.105 \\
\hline 2. Freq. of shellfish consumption & -0.285 & 0.035 & 3. Freq. of eating potatoes & -0.299 & 0.027 \\
\hline 3. Deep fried, broiled or smoked seafood & 0.308 & 0.022 & 4. Amount of fruits consumption & 0.221 & 0.105 \\
\hline 4. Freq. of deep fried or smoked seafood & 0.269 & 0.047 & 5. Freq. of stir-fried dishes & 0.296 & 0.028 \\
\hline 5. Speed of eating & 0.295 & 0.029 & 6. Freq. of skipping meals (less skip- & 0.211 & 0.123 \\
\hline 6. BMI & 0.373 & 0.005 & ping +$)$ & & \\
\hline 7. Energy consumption & 0.388 & 0.003 & 7. BMI & 0.206 & 0.131 \\
\hline Between total fat intake and: & & & Between total vitamin $\mathrm{C}$ intake and : & & \\
\hline 1. Deep fried, broiled or smoked seafood & 0.357 & 0.007 & 1. Freq. of eating green leafy vegetables & 0.311 & 0.021 \\
\hline 2. Freq. of eating vitamin $C$ rich fruits & -0.270 & 0.046 & 2. Freq. of eating dark colored vegetables & 0.276 & 0.041 \\
\hline 3. Amount of salad dressing use & 0.280 & 0.039 & 3. Freq. of eating stir-fried dishes & 0.275 & 0.042 \\
\hline 4. Freq. of eating snacks at night & 0.351 & 0.009 & 4. Length of time to eat breakfast & 0.281 & 0.038 \\
\hline 5. Amount of fruits consumption & -0.284 & 0.036 & & & \\
\hline 6. BMI & 0.391 & 0.003 & Between total iron intake and: & & \\
\hline 7. Energy consumption & 0.396 & 0.003 & 1. Freq. of eating canned fish products & 0.334 & 0.013 \\
\hline & & & 2. Freq. of eating potatoes & -0.306 & 0.023 \\
\hline Between total salt (or sodium) intake & & & 3. Amount of fruits consumption & 0.253 & 0.062 \\
\hline and: & & & 4. Freq. of eating stir-fried dishes & 0.275 & 0.042 \\
\hline $\begin{array}{l}\text { 1. Deep fried, broiled or smoked sea- } \\
\text { food }\end{array}$ & 0.399 & 0.003 & 5. Freq. of skipping meals & 0.214 & 0.117 \\
\hline 2. Freq. of eating vitamin $\mathrm{C}$ rich fruits & -0.319 & 0.018 & Between total calcium intake and: & & \\
\hline 3. Amount of salad dressing use & -0.239 & 0.079 & 1. Freq. of eating turkey or chicken & 0.309 & 0.022 \\
\hline 4. Freq. of eating snacks at night & 0.370 & 0.005 & 2. Freq. of eating seafood & 0.280 & 0.038 \\
\hline 5. Amount of fruits consumption & -0.293 & 0.030 & 3. Freq. of eating shellfish & 0.279 & 0.039 \\
\hline 6. BMI & 0.305 & 0.023 & 4. Deep fried, broiled or smoked seafood & 0.381 & 0.004 \\
\hline & & & 5. Freq. of eating green leafy vegetables & -0.299 & 0.027 \\
\hline Between total vitamin A intake and: & & & 6. Freq. of eating steamed dishes & 0.268 & 0.047 \\
\hline 1. Freq. of fast food consumption & -0.380 & 0.004 & 7. Freq. of eating out & -0.285 & 0.035 \\
\hline 2. Freq. of bean product consumption & 0.341 & 0.011 & 8. BMI & 0.227 & 0.096 \\
\hline $\begin{array}{l}\text { 3. Freq. of eating tofu, abura-age and } \\
\text { soy milk }\end{array}$ & -0.262 & 0.053 & & & \\
\hline 4. Freq. of dark colored vegetables & 0.230 & 0.091 & & & \\
\hline 5. Freq. of eating deep fried or rich food & -0.316 & 0.019 & & & \\
\hline 6. Freq. of eating out & -0.264 & 0.036 & & & \\
\hline
\end{tabular}


Q-22.

How often do you eat eggs?

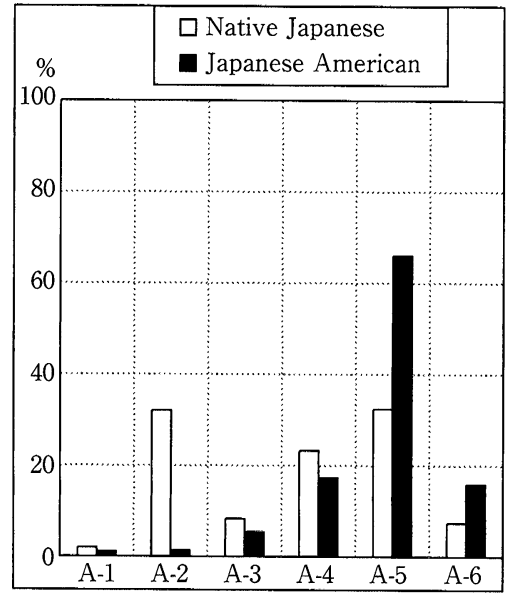

A-1 : More than 2 eggs a day

A-2 : 1 egg a day

A-3 : 5-6 eggs a week

A-4 : 3-4 eggs a week

A-5 : 1-2 eggs a week

A-6 : Never

Q-28.

How often do you eat vegetables?

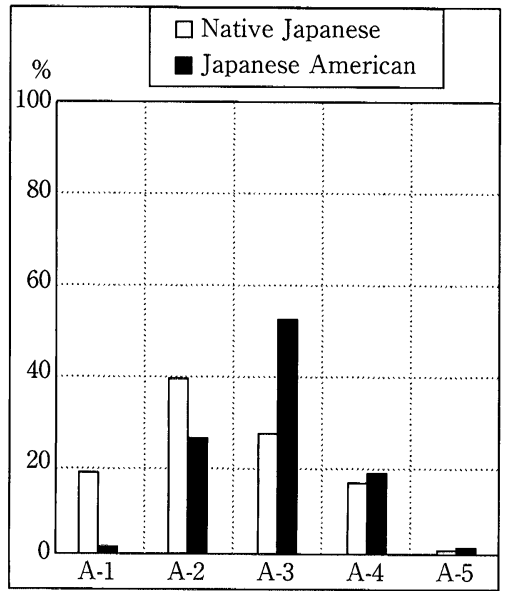

A-1 : 3 times a day or more

A-2 : Twice a day

A-3 : Once a day

A-4 : 2-3 times a week

A-5 : Seldom
Q-23

If you answered "Never" to Question 22, why don't you eat eggs?

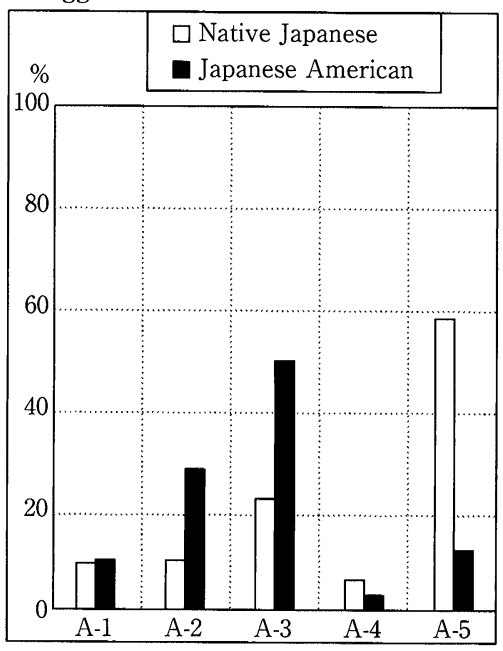

A-1 : I dislike eggs

A-2 : I have high cholesterol

A-3 : Because they contain high Cholesterol A-4 : I am allergic to them A-5 : Others

Q-30.

How often do you eat any green Leafy vegetables (such as spinach, and mustard greens)?

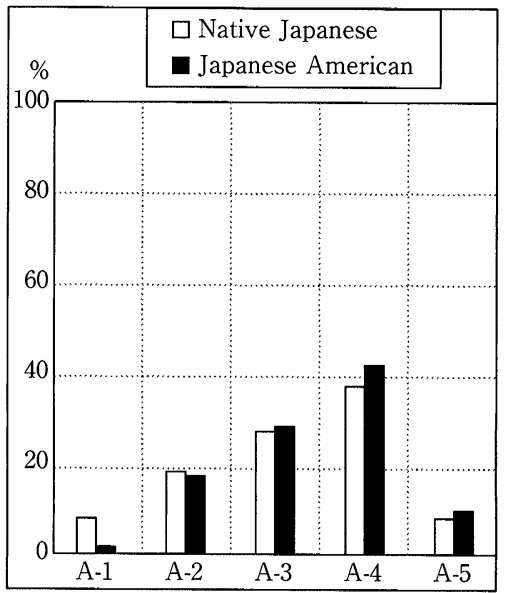

A-1 : Twice a day

A-2: Once a day

A-3 : 3-4 times a week

A-4 : 1-2 times a week

A-5 : Seldom

Figure 4 Comparison of dietary habits between Japanese Americans and native Japanese 
Q-38.

How often do you eat dishes

with about 2 tablespoons of

vinegar, lemon, or lime?

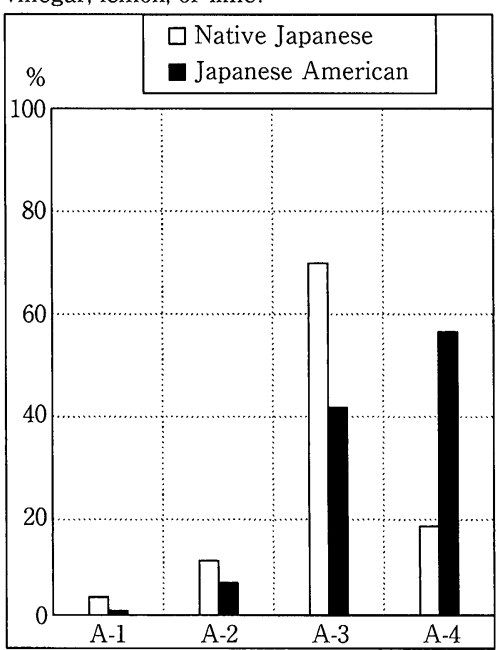

A-1 : More than twice a day

A-2 : Every day

A-3 : 2-3 times a week

A-4 : Seldom

Q-51.

Do you skip meals?

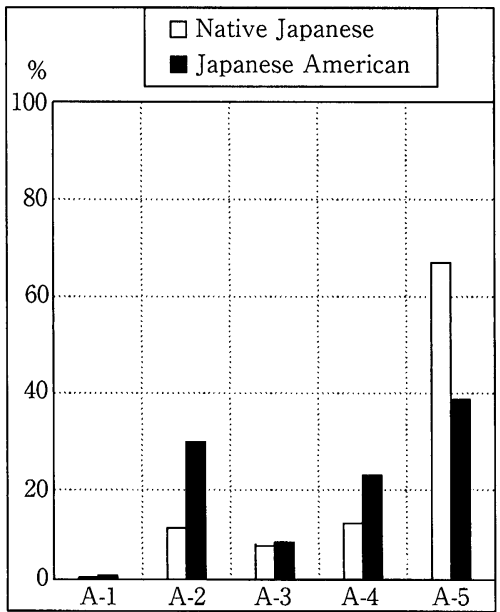

A-1 : I skip at least twice a day

A-2 : I skip at least twice one meal a day

A-3 : I skip 3-4 meals a week

A-4 : I skip 1-2 meals a week

A-5 : I never skip meals
Q-47.

Do you eat evening snacks or late-night snacks?

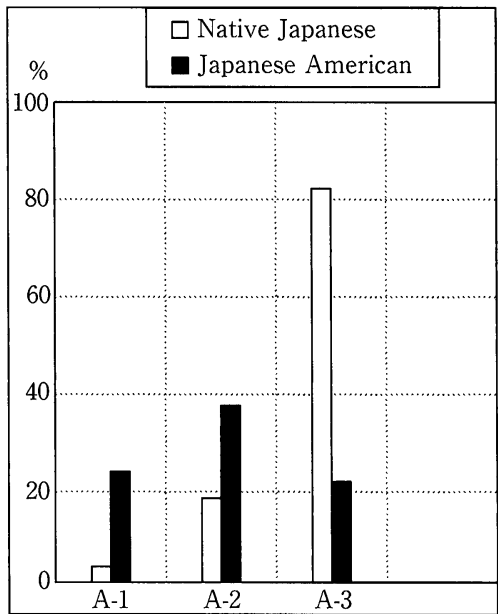

A-1 : Almost every day

A-2 : 3-4 times a week

A-3 : Never

Q-64.

How full are you after you have eaten your dinner?

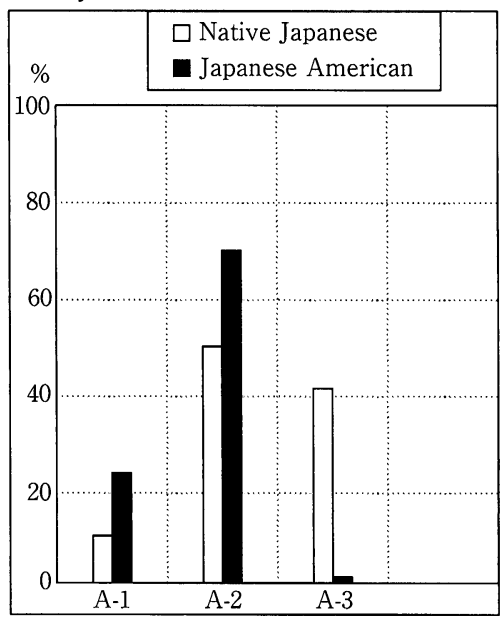

A-1 : Very full

A-2 : Just rich, $70-80 \%$

A-3 : Very light

Figure 4 
ese, 830 Japanese Americans and 1,841 native Japanese were asked to fill out the questionnaire on eating habits. Figure 4 shows the results of responses to questions to which Japanese Americans and native Japanese gave remarkably different answers. The results are summarized as follows.

(1) Native Japanese eat eggs more frequently than Japanese Americans (Question 22), and most Japanese Americans who never eat eggs cited their cholesterol value and the high cholesterol content in eggs as the reason (Question 23). This Implies that education regarding cholesterol in the U.S. is disseminated well among Japanese Americans.

(2) A greater diversity of vegetable (Question $28,30)$,

(3) Dishes with vinegar (Question 38) appeared more frequently in native Japanese than in Japanese Americans.

(4) Japanese Americans eat late-night snacks (Question 47),

(5) Skip meals (Question 51) more frequently than native Japanese.

(6) $99 \%$ of Japanese Americans eat until feeling full or feeling $70-80 \%$ full at dinner, while $59 \%$ of Native Japanese do so (Question 64).

\section{Discussion and Conclusion}

The Ni-Hon-San study, conducted among Japanese men living in Hiroshima, Japanese American men in Hawaii and San Francisco about 30 years ago, reported mean cholesterol and prevalence of coronary heart disease increasing in the above-listed order. Since living habits and lifestyle of both Japanese and American people have been dramatically changed during the past 30 years a joint study by the PDPC and EARI was launched. As mentioned before, the degree of atherosclerosis is higher in Japan- ese Americans than in native Japanese; the results of survey on eating habits suggest that such a difference depends to some degree on the difference in eating habits between the two populations. This is also supported by our survey results showing that most Japanese Americans preferred fat-rich food, consumed less potatoes and vegetables, and had irregular eating habits.

Based on the results of the present study, the health status of Japanese Americans in Seattle are considered to be quite similar to that of Japanese Americans in San Francisco, as far as cholesterol levels and prevalence of coronary heart disease (Kagan and Yano, 1996; Namekata, 1998; Ohara et al., 1991).

In conclusion, living in the U.S. mainland may be a disadvantage to Japanese Americans in terms of health. It is true that Japanese Americans are much concerned about their health, reflecting their lower percentages of drinkers and smokers compared with other Americans. Namekata and coworkers (1995) previously reported extremely low physical activity level in Japanese Americans in Seattle (20\% active in men and $6 \%$ active in women), compared with those of Hawaii ( $67 \%$ active in men). A low physical activity level can result in an increased BMI level and a decrease in HDL cholesterol which is considered to prevent atherosclerosis (Ohara et al., 1991). Also, a low percentage of drinkers among Japanese Americans might have same advense nalation on HDL cholesterol levels, thereby increase the degree of atherosclerosis among the Japanese American population in Seattle. Generally, nutrition and food culture is considered to be positively associated with health, but it is not easy to determine how they actually affect health or a specific disease. In this study, we used the questionnaire specifically designed for Japanese Americans and tested for ef- 
fectiveness by comparing the survey results between Japanese Americans and native Japanese. Dietary fiber deficiency due to inadequate vegetable intake and less intake of vitamins $\mathrm{A}$ and $\mathrm{C}$ which act as antioxidants could be largely involved in the acceleration of atherosclerosis among Japanese Americans in Seattle, although we need to confirm this in future studies.

\section{Acknowledgment}

The authors express their appreciation for their assistance in screening. This study was partly supported by the grants from Pfizer Research Foundation, Research Committee on Prevention of Atherosclerosis.

\section{References}

Ball M, Mann J (1988): Lipids and Heart Disese; A practical Approach: 85-92, Oxford Univ. Press, (London)

Hallcock P (1934): Arterial elasticity in man in relation to age as evaluated by the pulse wave velocity method. Arch Int Med, 54, 770-798

Hasegawa M (1970): Hito no doumyaku myakuha sokudo no kisoteki kennkyu (A fundamental study on human aortic pulse wave velocity), Jikei Ikadaigaku Zattshi, 85, 742-760

Kagan A, Yano K (1996): Ni-Hon-San Study in "The Honolulu Heart Program: An Epidemiological Study of Coronary Heart Disease and Stroke", edited by Kagan A, 21-32. Harwood Academic Publishers, (Amsterdam)

Kokumineisei no Doukou (1993): Dai4kai zenkoku shinjunkanki shitssukan chousa (Summary of the 4th National Cardiovascular Disease Examination Survey), Kosei no shihyou, 40, 36-48

Kokumineisei no Doukou (2001): (Trends of Nation's Health), Kosei no shihyou, 48, 87

Marmot MG, Syme SL, Kagan A et al. (1975): Epidemiological studies of coronary heart disease and stroke in Japanese men living in Japan, Hawaii and California: prevalence of coronary and hypertensive heart disease and associated factors, Am J Epidemiol 102, 514-525

Morishita T, Yamaguchi R, Suzuki A et al. (1985):
Doumyaku kouka ni yoru henka no choukikansatsu no ekigakuteki kaiseki (Long term individual changes of arteriosclerosis by epidemiological assay), Nihon doumyaku kouka gakukaishi, 12, 1463-1468

Namekata T, Moore D, Suzuki K et. al. (1995): Seattle zaijuu nikkeiamerikajin no ketchu koresuteroru to raifusutairu to no kankei (A study of the association between cholesterol level and life style factors among Seattle Japanese Americans) Koseinoshihyou, 12, 14631468

Namekata T, Moore D, Suzuki K et al. (1997): Seattle nikkeiamerikajin ni okeru daidoumyaku myakuhasokudo to doumyakukouka riskuyouin tono kanren ni kansuru kenkyu (A study of the association between the aorotic pulse wave velocity and atherosclerotic risk factors among Japanese Americans in Seattle, U.S.A.) Nichikoueishi 44, 942-954, 1997

Namekata T (1998): Association between atherosclerotic indicators and lifestyle factors: Seattle Nikkei Health Study. Proceedings of the 27th International Medical Advisory Conference, 143-151

Ohara K, Kiga M, Sakai Y et al. (1991): Factors associated with high density lipoprotein cholesterol in Japanese American telephone executives. Am J Epidenmiol 131, 137-14

Otsuka F (1973): Doumyaku myakuha sokudo to aorota no soshikihenka ni tsuite (A study on relationship between pulse wave velocity of human aorta and its postmortem histo-pathology), Jikei Ikadaigaku zattshi 88, 1-16

Suzuki K, Mori M, Masuya N et al. (1996): Doumyakumyakuha sokudo no ekigaluteki kenkyu (1) Myakuhasokudo no kouketsuatsu, ganteimoumaku no kouketsuatsusei henka oyobi shindenzujou no kyoketsusei henkashoken to no kankei ni tsuite (Epidemiological studies of atherosclerosis (I): Association of aortic pulse wave velocity with hypertension, arteriolar sclerotic changes in the retina, and ischemic ECG changes), Doumyakukouka 23, $715-720$

Ulene A (1989): Count out cholesterol: American Medical Association Campaign Against Cholesterol, Feeling Fine Program Inc. (New York)

(Received 2. 24, 2004 ; Accepted 8. 5, 2004) 